\title{
Transforming growth factor $\beta$ isoforms in human optic nerve heads
} Janethe D O Pena, Andrew W Taylor, Cynthia S Ricard, Ivonne Vidal,
M Rosario Hernandez
Department of Ophthalmology and Visual Sciences, Washington University School of Medicine, St Louis, USA

J D O Pena

C S Ricard

I Vidal $^{\star}$

M R Hernandez

Department of

Anatomy and

Neurobiology,

Washington University

School of Medicine,

St Louis, USA

M R Hernandez

Schepens Eye

Research Institute and the Department of

Ophthalmology,

Harvard Medical

School, Boston, USA

A W Taylor

*Present address:

Department of Neuroscience Graduate Program,

University of Pennsylvania,

Philadelphia, PA, USA

Correspondence to:

M Rosario Hernandez, DDS,

Department of

Ophthalmology and Visual

Sciences, Washington

University School of

Medicine, 660 S Euclid

Avenue, Box 8096, St Louis, MO 63110, USA.

Accepted for publication 30 July 1998

\begin{abstract}
Aim-To determine if the isoforms of transforming growth factor $\beta$ (TGF- $\beta$ ) are present in fetal, normal adult, and glaucomatous optic nerve heads.

Methods-To localise cells synthesising TGF- $\beta$, optic nerve heads were stained using antibodies to TGF- $\beta 1$, TGF- $\beta 2$, and TGF- $\beta 3$. To demonstrate synthesis, human optic nerve heads from fetal, glaucomatous, and normal age matched subjects were explanted, cultured overnight, and the culture supernatant was assayed for the presence of TGF- $\beta 1$ and TGF- $\beta 2$ by bioassay. In addition, semiquantitative RT-PCR was performed to determine the gene expression pattern of TGF- $\beta 2$.

Results-Immunohistochemistry of glaucomatous samples revealed the presence of intense staining for TGF- $\beta 2$ primarily in astrocytes, whereas TGF- $\beta 1$ was localised to blood vessels. No TGF- $\beta 3$ immunoreactivity was observed. There was little or no expression of TGF- $\beta$ in normal optic nerve heads. Optic nerve heads from glaucomatous eyes released $70-100$-fold more TGF- $\beta 2$ than normal age matched optic nerve heads. Fetal optic nerve heads released $90-100$-fold more TGF- $\beta 2$ than normal adult optic nerve heads. TGF- $\beta 1$ was undetectable by bioassay in all samples tested. There was no apparent increase in TGF- $\beta 2$ gene expression in glaucomatous and fetal eyes, suggesting post-transcriptional regulatory mechanisms.

Conclusions-These results demonstrate that TGF- $\beta 2$ is produced in high levels in the fetal and glaucomatous optic nerve heads, perhaps by a mechanism of posttranscriptional regulation. TGF- $\beta$ may be important during development of the optic nerve head and, in glaucoma, TGF- $\beta 2$ may be a mediator of astrocyte reactivation and extracellular matrix remodelling in the lamina cribrosa.

(Br f Ophthalmol 1999;83:209-218)
\end{abstract}

Remodelling of the extracellular matrix (ECM) in the optic nerve head, including changes in fibrillar collagens, basement mem- brane components, and elastin is a morphological feature of glaucomatous optic neuropathy. ${ }^{1}$ The changes in the ECM of the optic nerve head are associated with the collapse of the cribriform plates and the cupping of the optic disc. The remodelling of the ECM may contribute, secondarily, to the loss of axons and visual impairment in glaucoma by disrupting the nutritional and mechanical support to the axons from the retinal ganglion cells as they pass through the lamina cribrosa of optic nerve head.

Transforming growth factor $\beta$ (TGF- $\beta$ ) plays a fundamental role in the biology of extracellular matrix, regulating not only the synthesis and degradation of specific components, but also the ability of cells to interact with ECM macromolecules. Control of these cell-matrix interactions may represent one of the principal mechanisms by which TGF- $\beta$ affects cell migration, differentiation, and growth in various tissues ${ }^{2}$ during normal morphogenesis and wound healing.

Three isoforms, TGF- $\beta 1$, TGF- $\beta 2$, and TGF- $\beta 3$, have been identified in human tissues, in many instances in a tissue specific pattern of distribution. In neural tissues, TGF- $\beta 1$ and TGF- $\beta 2$ are expressed preferentially in the central nervous system (CNS); whereas TGF- $\beta 1$ is the predominant isotype in peripheric nerves. ${ }^{3}$ In the eye, TGF- $\beta 1$ and

Table 1 Clinical data of glaucoma cases

\begin{tabular}{lllll}
\hline Sample & Age/sex & $\begin{array}{l}\text { Cup/ disc } \\
\text { ratio }\end{array}$ & $\begin{array}{l}\text { Visual } \\
\text { field }\end{array}$ & Experiment \\
\hline 1 & $58 / \mathrm{M}$ & 0.9 & 4 & IHC \\
2 & $74 / \mathrm{F}$ & 0.9 & 3 & IHC \\
3 & $78 / \mathrm{M}$ & 0.9 & 3 & IHC \\
4 & $71 / \mathrm{M}$ & 0.6 & 2 & IHC \\
5 & $51 / \mathrm{F}$ & 0.9 & 4 & IHC \\
6 & $51 / \mathrm{F}$ & 0.9 & 4 & IHC \\
7 & $91 / \mathrm{F}$ & 0.7 & 2 & IHC \\
8 & $67 / \mathrm{F}$ & 0.5 & 2 & IHC \\
9 & $67 / \mathrm{F}$ & 0.4 & 2 & IHC \\
10 & $69 / \mathrm{M}$ & NA & 2 & IHC \\
11 & $92 / \mathrm{M}$ & NA & 2 & IHC \\
12 & $77 / \mathrm{M}$ & 0.9 & 4 & BA \\
13 & $77 / \mathrm{M}$ & 0.9 & 4 & BA \\
14 & $77 / \mathrm{M}$ & NA & 2 & BA \\
15 & $53 / \mathrm{M}$ & NA & 2 & RT-PCR \\
16 & $67 / \mathrm{F}$ & NA & 3 & RT-PCR \\
17 & $92 / \mathrm{M}$ & NA & 3 & RT-PCR \\
\hline
\end{tabular}

*Visual field: 1 = no defect; 2 = increasing scotoma; 3 = significant defect; $4=$ loss of central field.

+IHC = immunohistochemistry; BA = bioassay; RT-PCR = reverse transcriptase polymerase chain reaction.

$\mathrm{NA}=$ information not available 

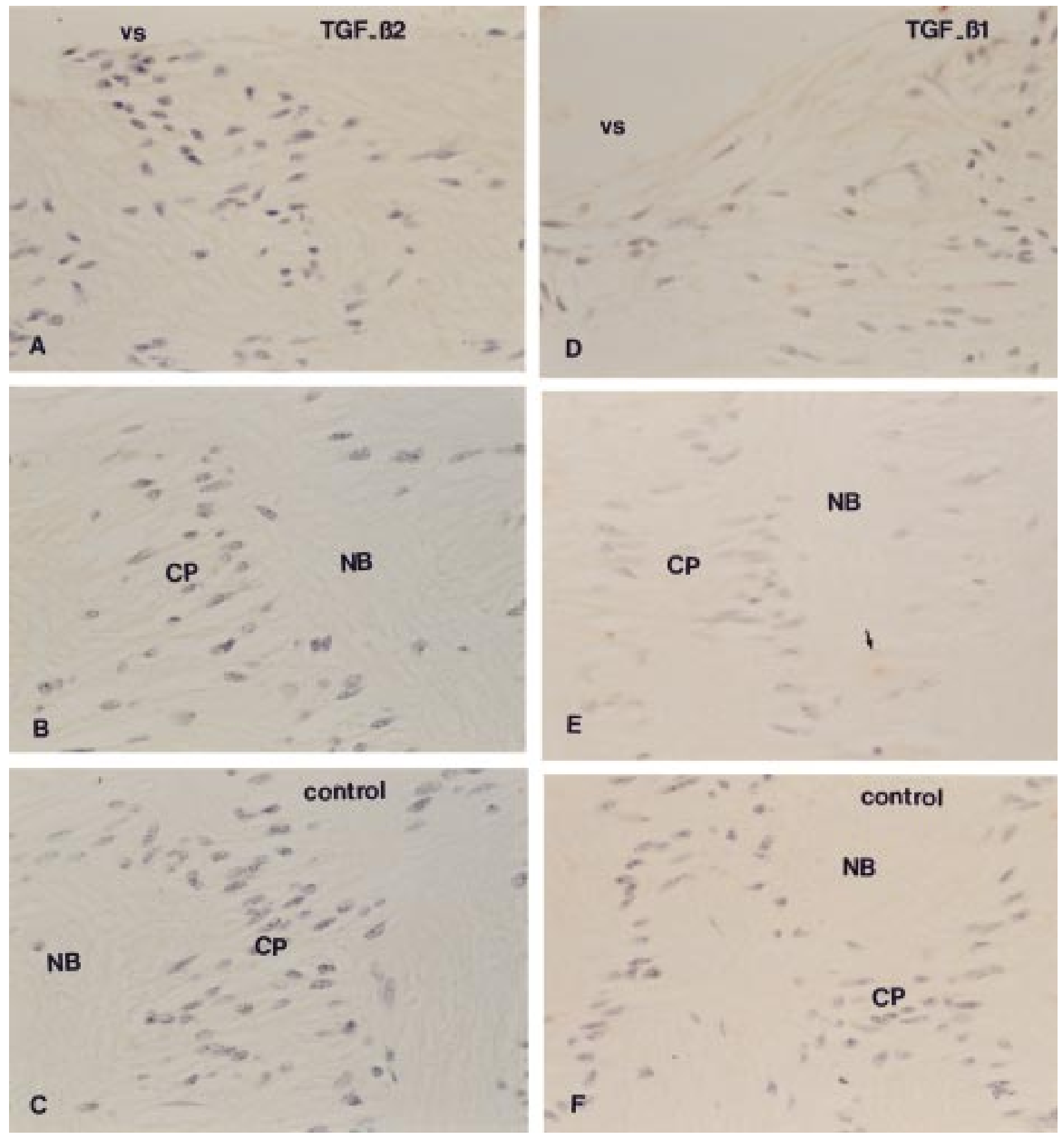

Figure 1 TGF- $\beta 1$ and TGF- $\beta 2$ immunoperoxidase staining in normal optic nerve head, donor age 68 years old. Little or no staining for TGF- $\beta 2$ is observed. Few blood vessels were stained with TGF- $\beta 1$ (arrow, E). (A) and (D) Prelaminar region; (B) and (E) lamina cribrosa; $(C)$ and $(F)$ negative controls. vs $=$ vitreal surface; $C P=$ cribriform plates, $N B=$ nerve bundles. $\times 375$.

TGF- $\beta 2$ are present in the anterior segment of human eyes $^{4}$ and TGF- $\beta 1$, TGF- $\beta 2$, and TGF- $\beta 3$ have been identified in the retina of humans, monkeys, and cats. ${ }^{5}$ In a preliminary report, TGF- $\beta 1$ has been identified in the postlaminar (myelinated) optic nerve by immunocytochemistry. ${ }^{6}$

Considering the effects of TGF- $\beta$ on extracellular matrix synthesis and degradation, and the reported presence of TGF- $\beta$ family members in other compartments of the human eye, we localised the cellular source of TGF- $\beta 1$, TGF- $\beta 2$, and TGF- $\beta 3$ by immunohistochemistry in fetal eyes and glaucomatous and normal age matched adult human tissues. We also investigated TGF- $\beta 2$ gene expression by relative reverse transcriptase polymerase chain reaction (RT-PCR) and the activity of TGF- $\beta 1$ and TGF- $\beta 2$ in explanted fetal, normal adult, and glaucomatous human optic nerve heads.

\section{Materials and methods}

IMMUNOHISTOCHEMISTRY FOR TGF- $\beta$ PROTEIN

Four pairs of human eyes (donor ages 65-81 years old) with no history of eye disease, seven eyes from seven different donors with history of advanced primary open angle glaucoma (donor ages 51-91 years old, samples 1-7 in Table 1), and four eyes from mild primary open angle glaucoma (donor ages 67-92 years 

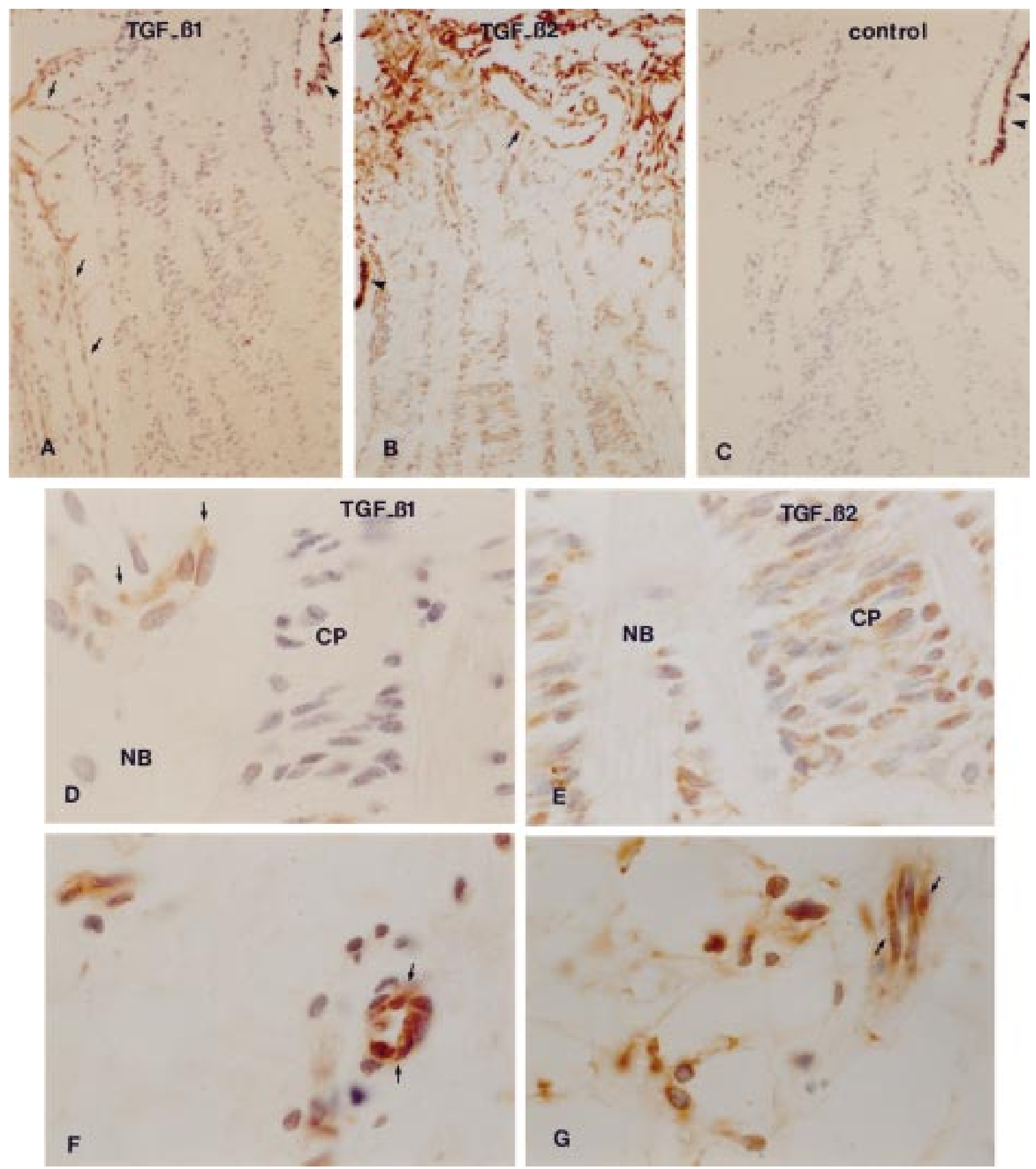

Figure 2 TGF- $\beta 1$ and TGF- $\beta 2$ immunoperoxidase staining in fetal optic nerve head (gestational age 24 weeks). TGF- $\beta 1$ immunoreactivity was restricted to blood vessels throughout the optic nerve head $(A, D)$ and TGF- $\beta 2$ reactivity was localised to the extracellular matrix and cells in the optic nerve head $(B, E)$. In the sclera, TGF- $\beta 1$ was detected in association with blood vessels $(F)$ and TGF- $\beta 2$ was associated with the vessels and fibroblasts $(G)$. (C) Illustrates the negative control. Arrows point to blood vessels and arrowheads point to the retinal pigment epithelium. $N B=$ nerve bundles; CP = cribriform plates. $(A-C) \times 75 ;(D-G) \times 750$.

old, samples $8-11$ in Table 1) were obtained from eye banks throughout the United States and from the Glaucoma Research Foundation (San Francisco, CA, USA). Eyes from donors with documented mild to advanced primary open angle glaucoma had cup/disc ratios of 0.4 to 0.9 , demonstrated visual field defects and were reportedly treated for glaucoma by ophthalmologists (Table 1). The interval between death and fixation was $2-4$ hours for the adult eyes. Three pairs of fetal eyes (gestational ages 18,20, and 24 weeks) were obtained through the Anatomical Gift Foundation (Laurel, MD, USA). Optic nerve heads from these fetal eyes were fixed immediately after enucleation in $10 \%$ buffered formaldehyde for at least 6 hours. The optic nerves were dissected, washed several times in phosphate buffered saline (PBS) containing $0.1 \%$ glycine, and processed for paraffin embedding accord- 
ing to standard procedures. Sagittal sections of $6 \mu \mathrm{m}$ were cut and placed on silane coated slides. Before immunostaining, slides were deparaffinised and incubated for 1 hour in PBS glycine at room temperature to reduce nonspecific binding. To visualise cells synthesising TGF- $\beta$, rabbit polyclonal antibodies with specificity for TGF- $\beta 1$, TGF- $\beta 2$, or TGF- $\beta 3$ were used (Santa Cruz Biotechnology, Santa Cruz, CA, USA). The anti-TGF- $\beta 1$ antibody recognises an epitope corresponding to amino acids $328-353$ at the carboxy terminus of TGF- $\beta 1$; the anti-TGF- $\beta 2$ antibody recognises an epitope corresponding to amino acids $352-377$ at the carboxy terminal of TGF- $\beta 2$, and the anti-TGF- $\beta 3$ antibody recognises an epitope corresponding to amino acids $350-375$ at the carboxy terminal of TGF- $\beta 3$. Corresponding antigenic peptides (Santa Cruz Biotechnology) or recombinant TGF- $\beta 1$ and TGF- $\beta 2$ (R\&D Systems, Minneapolis, MN, USA) were obtained and used to preabsorb primary antibody for negative controls. These antibodies were purified by peptide affinity chromatography and tested for isoform specificity by the company, and have also been used in previous publications. ${ }^{7}{ }^{8}$ Antibodies were used at 1:200 dilution and all steps of the staining process were carried out at room temperature. Slides were preincubated with $5 \%$ milk for 30 minutes, rinsed, and then incubated with primary antibody for 30 minutes. Biotinylated secondary antibody was placed on the sections and incubated for 30 minutes, washed with PBS, and reacted with the streptavidinperoxidase conjugate (Vector Laboratories, Burlingame, CA, USA) for 30 minutes. After a PBS wash, the bound antibody-peroxidase complexes on the sections were visualised using a DAB substrate solution consisting of $1.5 \mathrm{mg} \mathrm{3,3-diaminobenzidine} \mathrm{tetrahydrochlo-}$ ride (DAB) and $50 \mu \mathrm{l}$ of $30 \%$ hydrogen peroxide, in $10 \mathrm{ml}$ of $0.1 \mathrm{M}$ TRIS, $\mathrm{pH}$ 7.6. The sections were incubated in the dark until brown staining appeared, at about 5-7 minutes, washed in PBS, counterstained with haematoxylin or nuclear fast red, dehydrated, and coverslipped with Permount. To confirm that the cells synthesising TGF- $\beta 2$ were astrocytes, sections from glaucomatous eyes (samples 3 and 11 in Table 1) were double stained using a monoclonal antibody against human glial fibrillary acid protein (GFAP; Sigma Chemical, St Louis, MO, USA) and a polyclonal antibody against TGF- $\beta 2$ (Santa Cruz Biotechnologies) followed by incubation with Rhodamine-Red and Cy-5 labelled secondary antibody mixture (Molecular Probes, Eugene, OR, USA). Slides were examined in a Nikon Optiphot-2 microscope and images were recorded using Kodak Royal Gold 400 ASA colour print film. Visualisation of the GFAP/ TGF- $\beta 2$ co-localisation was done in a Zeiss LSM 410 laser confocal microscope and images were printed using an Epson Stylus photo printer.

Representative sections of all samples were stained simultaneously to control variation in the reactions. Negative controls were performed by absorbing the primary antibody
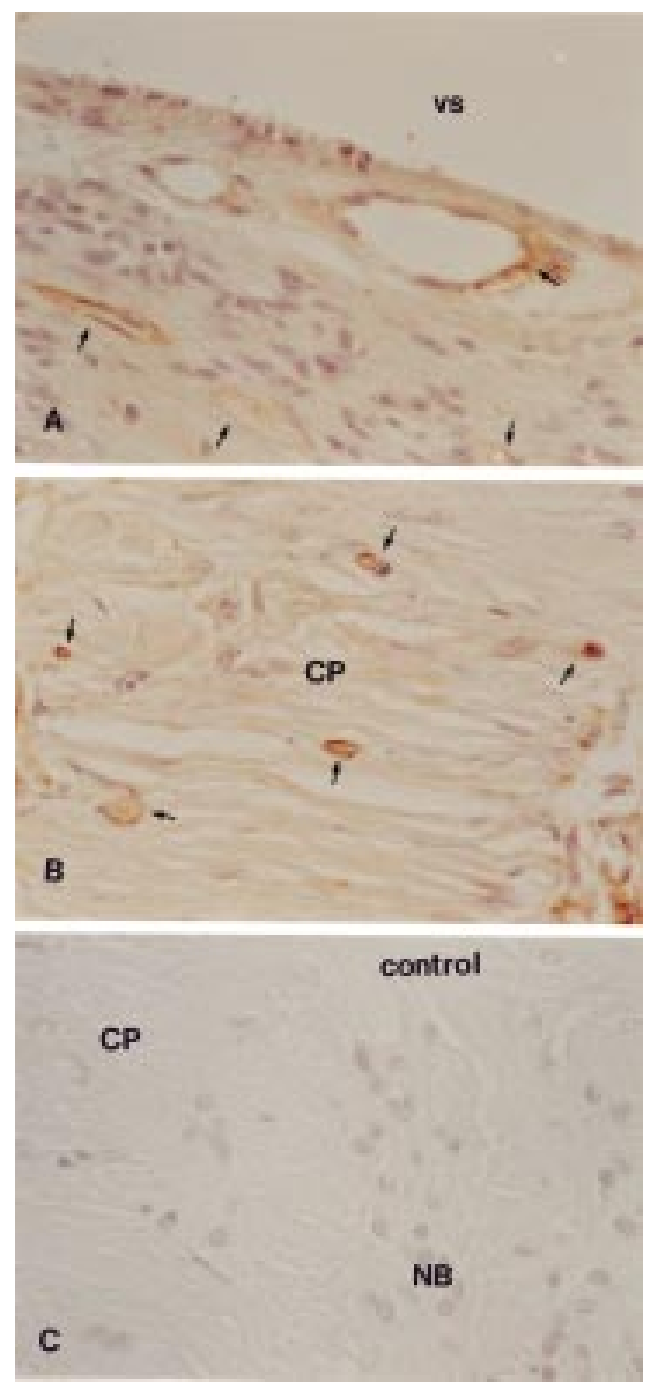

Figure 3 TGF- $\beta 1$ immunoperoxidase staining in advanced primary open angle glaucoma, donor age 78 years old. Note staining around blood vessels (arrows). (A) Prelaminar region; (B) lamina cribrosa; (C) negative control. $v s=$ vitreal surface $; C P=$ cribriform plates $; B=$ nerve bundles. $\times 350$.

with TGF- $\beta 1$, TGF- $\beta 2$, or TGF- $\beta 3$ peptides (Santa Cruz Biotechnology) or recombinant TGF- $\beta 1$ and TGF- $\beta 2$ (R\&D Systems) or by replacing the primary antibody with nonimmune rabbit serum.

TGF- $\beta$ BIOASSAY

Explant preparation

Eight normal human eyes from different individuals (ages 55-85 years old) with no history of eye diseases, and three eyes from two patients with advanced primary open angle glaucoma (age 77 years old, samples $12-14$ in Table 1) were used in this study. The eyes were enucleated within 2-6 hours after death, kept at $4^{\circ} \mathrm{C}$ in a sterile humidified container, and all eyes were processed within 12-18 hours after death. The optic nerves were dissected under a microscope and cleared of surrounding tissues as previously described. ${ }^{9}{ }^{10}$ Each optic nerve head (approximate weight $15 \mathrm{mg}$ ) was divided into four pieces and incubated in a $35 \mathrm{~mm}$ dish in $0.5 \mathrm{ml}$ of serum free medium, RPMI 1640 media supplemented with a $1 / 500$ dilution of 

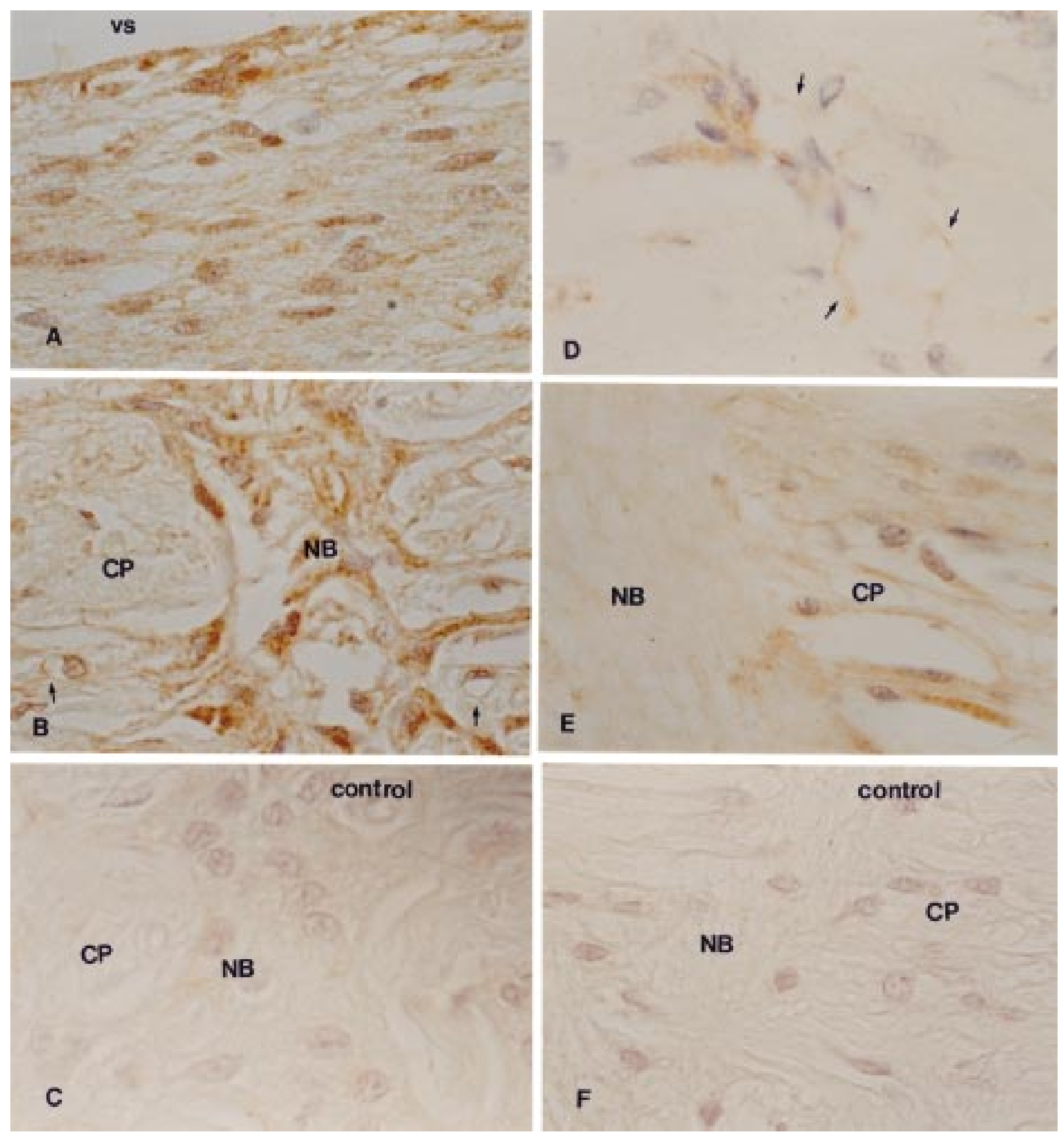

Figure 4 TGF- $\beta 2$ immunoperoxidase staining in advanced $(A, B$, and $C)$ and mild $(D, E$, and $F)$ primary open angle glaucoma, donor ages 74 years old (advanced glaucoma) and 67 years old (mild glaucoma). Note widespread staining of astrocytes and the extracellular matrix throughout the optic nerve head of the sample from with advanced glaucoma ( $A$ and $B$ ). Reactivity in blood vessels was also noted (arrow). In the mild glaucoma sample, few astrocytes and blood vessels (arrows) were labelled in the prelaminar region (D) and in the lamina cribrosa, with little staining in the extracellular matrix $(E)$. (C) and $(F)$ are negative controls. vs = vitreal surface; $N B=$ nerve bundles; $C P=$ cribriform plates. $\times 750$.

ITS+ (insulin, transferrin, selenium, bovine serum albumin, and linoleic acid) universal culture supplement (Collaborative Biomedical Products, Bedford, MA, USA). In addition to the adult tissues, three pairs of human fetal eyes (ages 18, 20, 22 weeks' gestation) were also used and prepared as above, except that optic nerve heads were left intact and each pair of nerves was combined, so that a similar amount of tissue was used for fetal and adult optic nerves (approximately $15 \mathrm{mg}$ tissue per sample). After 24 hours of incubation at $37^{\circ} \mathrm{C}$ and $5 \%$ carbon dioxide the supernatants were assayed for TGF- $\beta$. Cell viability was assessed by culturing the optic nerve explants in EMEM containing $10 \%$ fetal bovine serum. Cell outgrowth was observed in all samples used for the bioassays.

\section{Standard Mv1Lu cell assay}

To measure total TGF- $\beta$, the mink lung epithelial cell $(\mathrm{Mv} 1 \mathrm{Lu})$ bioassay was used. In this study, TGF- $\beta$ bioassay was used for measuring total TGF- $\beta$ proteins in the culture supernatants, and because of the acid treatment, it was not possible to distinguish between latent and 

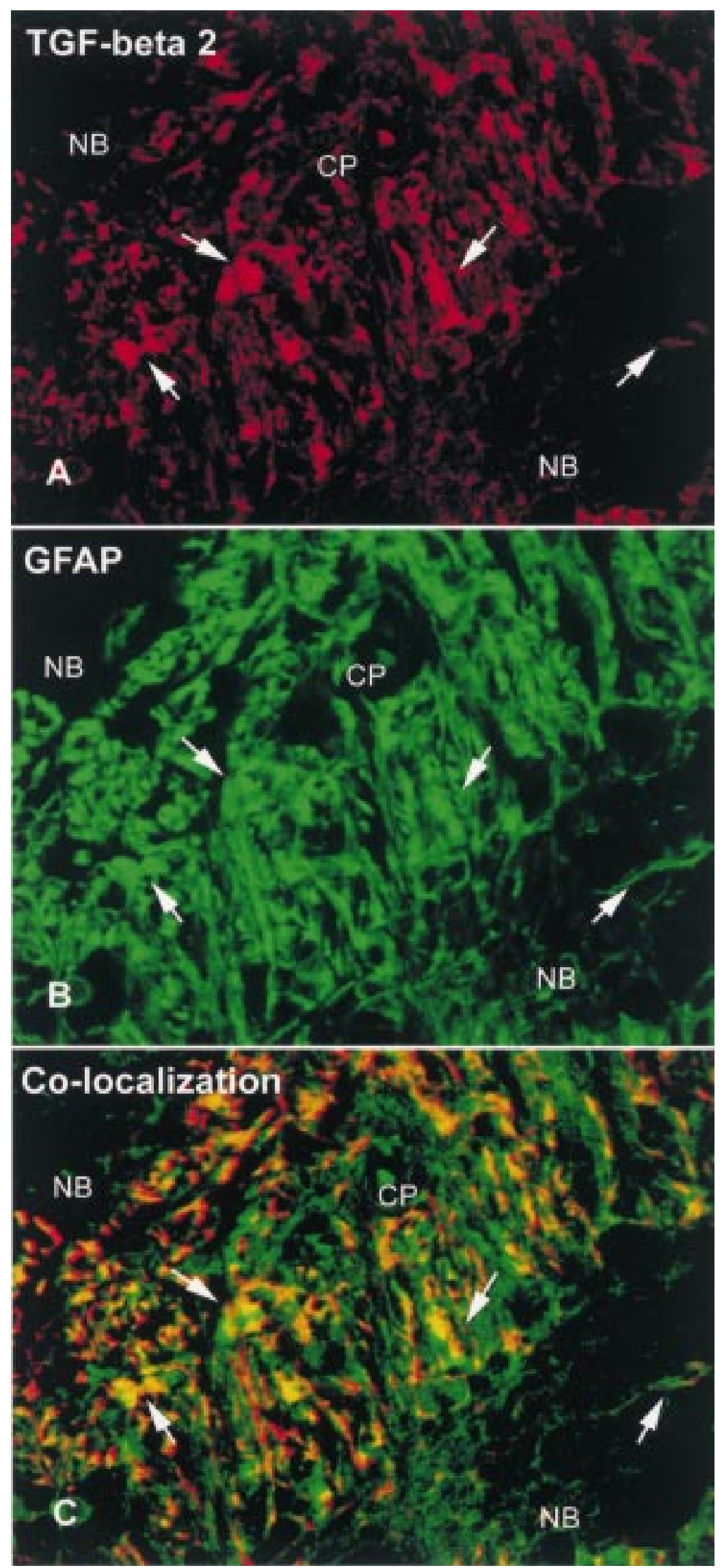

Figure 5 Co-localisation of TGF- $\beta 2$ and GFAP by immunofluorescence in the lamina cribrosa of a glaucomatous donor (age 92 years old). In (A) immunoreactivity for TGF- $\beta 2$ is localised to cells inside the cribriform plates (CP) and in the nerve bundles (NB). These cells are also GFAP positive, confirming their identity as astrocytes (B). (C) Illustrates the co-localisation of TGF- $\beta 2$ and GFAP. Arrows point to some of the cells that show double staining. $\times 400$. active forms of TGF- $\beta$. Specificity was determined by adding neutralising antibodies against specific TGF- $\beta$ isoforms to the culture supernatants. To perform the assay, supernatants from the optic nerve explants were transiently acidified ( $\mathrm{pH} 2.0$ ) by adding $5 \mu \mathrm{l}$ of $1 \mathrm{M} \mathrm{HCl}$ per $100 \mu \mathrm{l}$ of supernatant and incubated for 1 hour at $4^{\circ} \mathrm{C}$. The acid was neutralised $(\mathrm{pH} 7.4)$ by adding $10 \mu \mathrm{l}$ of a $1: 1(\mathrm{v} / \mathrm{v})$ mixture of $1 \mathrm{M}$ $\mathrm{NaOH}$ and $1 \mathrm{M}$ HEPES to the acidic supernatant. To $100 \mu \mathrm{l}$ of diluted supernatant in the wells of a 96 well flat bottom Falcon plate (Lincoln Park, NJ, USA), $100 \mu \mathrm{l}$ of $1 \times 10^{4} \mathrm{Mv} 1 \mathrm{Lu}$ cells (No CCL64, ATCC) were added in EMEM with $0.5 \%$ fetal bovine serum (Hyclone). The cultures were incubated at $37^{\circ} \mathrm{C}$ for 20 hours and $20 \mu \mathrm{l}$ of $1 \mu \mathrm{Ci}^{3} \mathrm{H}$ thymidine were added. The explants were then incubated for an additional 4 hours. Incorporated ${ }^{3} \mathrm{H}$ thymidine was measured by scintillation counting as counts per minute (cpm). The amount of TGF- $\beta$ in the supernatants was determined by comparing cpm of explant supernatant treated cells with a standard curve made from CPM of explants treated with known amounts of TGF- $\beta$ (R\&D Systems). The limits of detection in our assay were between $1 \mathrm{pg} / \mathrm{ml}$ and 10 $\mathrm{ng} / \mathrm{ml}$. To determine the specific isotype of TGF- $\beta$, antisera with neutralising specificity against either human TGF- $\beta 1$ or TGF- $\beta 2$ $(\mathrm{R} \& \mathrm{D} \text { Systems) })^{11}{ }^{12}$ were used in the TGF- $\beta$ bioassay. The antibodies were used at 10 times their $50 \%$ neutralising dose. The neutralising anti-TGF- $\beta 1$ was a chicken IgY against recombinant human TGF- $\beta 1$, used at $10 \mu \mathrm{g} / \mathrm{ml}$. The neutralising TGF- $\beta 2$ was a goat anti-porcine TGF- $\beta 2$ that cross reacts only with TGF- $\beta 2$ isotypes from mammals, used at $20 \mu \mathrm{g} / \mathrm{ml}$. The transiently acidified supernatants were incubated with anti-TGF- $\beta 1$ or anti-TGF- $\beta 2$ neutralising antibodies for 1 hour at $37^{\circ} \mathrm{C}$ before being assayed.

\section{RELATIVE RT-PCR FOR TGF- $\beta 2$}

To measure relative levels of TGF- $\beta 2$ mRNA, total RNA was extracted from minced normal and glaucomatous optic nerve heads (samples 15-17 in Table 1) using TriZol according to manufacturer's recommendations (Gibco/ BRL, Gaithesburg, MD, USA) for minimisation of DNA carryover. As positive controls, total RNA was extracted from cultured brain and optic nerve head astrocytes (type 1B astrocytes). For each sample, $1.0 \mu \mathrm{g}$ total RNA was DNase treated to remove any residual contaminating genomic DNA and reverse transcribed to cDNA with $500 \mathrm{ng}$ of oligo dT and 50 ng random hexamers using Superscript II and kit components (Gibco/BRL) in a $50 \mu \mathrm{l}$ reaction volume. For PCR, $1 \mu \mathrm{l}$ of the cDNA was used as template for 25 cycles of amplification in $50 \mu \mathrm{l}$ reaction volume with either $\beta$ actin or TGF- $\beta 2$ amplimers (Clontech). Under these conditions TGF- $\beta 2$ amplification did not produce PCR products visible by ethidium bromide staining, so a second set of primers was designed for nested PCR. These 20-mer primers were based on sequences immediately adjacent to the $3^{\prime}$ ends of the Clontech amplimers in GenBank accession 
Table 2 Semiquantitative analysis of TGF- $\beta$ immunohistochemistry in human optic nerve heads

\begin{tabular}{|c|c|c|c|c|c|c|}
\hline & \multicolumn{2}{|l|}{$T G F-\beta 1$} & \multicolumn{4}{|l|}{$T G F-\beta 2$} \\
\hline & \multicolumn{2}{|c|}{ Prelamina/lamina } & \multicolumn{2}{|l|}{ Prelamina } & \multicolumn{2}{|l|}{ Lamina } \\
\hline & Astrocytes & Vessels & Astrocytes & Vessels & Astrocytes & Vessels \\
\hline Fetal $(n=3)$ & - & + & ++ & + & ++ & + \\
\hline Normal $(n=4)$ & - & $+/-$ & - & - & - & - \\
\hline Mild glaucoma $(n=4)$ & - & $+/-$ & ++ & + & ++ & + \\
\hline Advanced glaucoma $(n=7)$ & - & + & +++ & + & +++ & + \\
\hline
\end{tabular}

$-=$ negative staining; $+/-=<10 \%$ labelled cells $+=10-25 \%$ labelled cells $;++=25-50 \%$ labelled cells; $+++=>50 \%$ labelled cells.

number M19154, resulting in a product of 438 bp. The first round of PCR, containing the predicted $503 \mathrm{bp}$ product from the Clontech primers, was diluted 10 -fold and $1 \mu \mathrm{l}$ used in a second amplification of 35 cycles. Therefore, the abundance of TGF- $\beta 2$ message was seven orders of magnitude less than that of $\beta$ actin.

\section{Results}

LOCALISATION OF TGF- $\beta$ PROTEIN IN THE OPTIC NERVE HEAD

Fetal optic nerve heads, as well as adult glaucomatous and normal eyes were stained for TGF- $\beta$ using specific antibodies to TGF$\beta 1$, TGF- $\beta 2$, and TGF- $\beta 3$.

In adult normal optic nerve heads, no detectable immunoreactivity for TGF- $\beta 1$ and TGF- $\beta 2$ was observed in association with glial cells, extracellular matrix or axons (Fig 1A, B, D). Occasionally, TGF- $\beta 1$ staining was observed in blood vessels (Fig $1 \mathrm{E}$ ). No immunoreactivity was observed for TGF- $\beta 3$ in any of the samples analysed (data not shown). Staining for TGF- $\beta 1$ and $-\beta 2$ was not remarkable in the postlaminar myelinated optic nerve (data not shown).

In the fetal optic nerve head, immunostaining for TGF- $\beta 1$ was associated with blood vessels in the nerve head, but not with glial cells or axons (Fig 2A, D). In the adjacent sclera, most blood vessels and few fibroblasts were labelled (Fig 2F). TGF- $\beta 2$ immunoreactivity was observed in most glial cells inside the neural tissues (Fig2B, E). These cells are presumably astrocytes or glial cell precursors. ${ }^{13}$ Blood vessels inside the nerve head were also labelled. No immunoreactivity was associated with axons. Most fibroblasts and blood vessels were labelled with TGF- $\beta 2$ antibody in the surrounding sclera (Fig 2G). No specific immunoreaction against TGF- $\beta 3$ was observed (data not shown). Negative controls did not show immunostaining (Fig 2C).

In glaucomatous optic nerve heads, immunoreactive TGF- $\beta 1$ was localised to small

Table 3 TGF- $\beta$ quantification by Mv1Lu cell bioassay of 24 hour culture supernatants from explanted human optic nerve heads

\begin{tabular}{lcl}
\hline & $\begin{array}{l}\text { Total TGF- } \beta 2 \\
\text { concentration } \\
(p g / m l(S E M))\end{array}$ & $\begin{array}{l}\text { Fold increase in } \\
\text { TGF- } \beta 2 \text { release } \\
\text { over normal adults }\end{array}$ \\
Sample* $^{*}$ & $8400(1400)$ & $70-100$ \\
Glaucoma $(\mathrm{n}=3)$ & $9000(1000)$ & $90-100$ \\
Fetal $(\mathrm{n}=3)$ & $109(26)$ & 0 \\
Normal adult $(\mathrm{n}=8)$ &
\end{tabular}

${ }^{\star}$ Glaucomatous donors $=77$ years old; fetal donors $=18,20$ and 22 weeks' gestation; normal donors $=55-85$ years old.

+Only TGF- $\beta 2$ antibody neutralised supernatant activity in the assay. blood vessels, capillaries, and venules of the prelaminar region (Fig 3A) and lamina cribrosa (Fig 3B). TGF- $\beta 1$ did not stain axons in the glaucomatous optic nerve, and occasionally stained perivascular cells (Fig 3B). Similar results were found in patients with mild glaucoma.

In the optic nerve heads of donors with moderate to advanced glaucoma $(n=6)$, TGF- $\beta 2$ immunoreactivity was abundant in astrocytes lining the vitreal surface and within astrocytes that occupy the prelaminar region (Fig 4A). In the lamina cribrosa, almost all cells were stained with TGF- $\beta 2$ antibody (Fig 4B). Most positive cells were located inside nerve bundles and few were present in the cribriform plates, and these cells have been previously identified as reactive astrocytes, based on positive GFAP staining (Fig 5) and morphological features. ${ }^{1415} \mathrm{~A}$ few blood vessels were also labelled with the TGF- $\beta 2$ antibody. Three optic nerve heads from donors with reportedly mild glaucomatous changes were also included in this study. Positive staining for TGF- $\beta 2$ was observed in astrocytes in the lamina cribrosa and in the prelaminar region (Fig 4D and E). However, not all astrocytes were labelled (Table 2). Very little immunoreactivity for TGF- $\beta 2$ was associated with blood vessels. Sections from glaucomatous optic nerve heads stained with preabsorbed primary antibody or with non-immune serum did not show any TGF- $\beta$ immunoreactivity (Fig 4C and F). Qualitatively, optic nerve heads with mild glaucoma appear to have fewer labelled astrocytes than optic nerve heads with advanced glaucoma damage (Table 2). No specific immunoreactivity was observed for TGF- $\beta 3$ in any of the samples tested (data not shown).

TGF- $\beta 2$ IS RELEASED BY EXPLANTED OPTIC NERVE HEADS

To determine if cells of the lamina cribrosa produce TGF- $\beta$, explants of human optic nerve heads were incubated in serum free media for 24 hours. The explant supernatant was assayed for the presence of TGF- $\beta$ using the standard mink lung (Mv1Lu) cell bioassay. Explant supernatants of optic nerve heads from normal adult eyes contained 109 (SD 26) $\mathrm{pg} / \mathrm{ml}$ of TGF- $\beta$ in comparison to the supernatant of explanted fetal optic nerve heads that contained 9200 (900) pg/ml TGF- $\beta$ (Table 3). Supernatant of explanted optic nerve heads from glaucomatous eyes contained 8400 (1400) $\mathrm{pg} / \mathrm{ml}$ of TGF- $\beta$ which is $70-100-$ fold more than normal age matched adult optic nerve head cultures (Table 3 ). In addition, neutralising anti-TGF- $\beta 1$ and anti-TGF- $\beta 2$ antibodies were used in the bioassay to identify the TGF- $\beta$ isotype released by the explanted optic nerve heads. In each case, only antiTGF- $\beta 2$ antibody neutralised the TGF- $\beta$ activity in the bioassay indicating the optic nerve heads, normal, fetal, or glaucomatous, secrete only TGF- $\beta 2$ in detectable amounts. The results suggest that under glaucomatous conditions the optic nerve head produces a higher amount of TGF- $\beta 2$ that is comparable to fetal production. 

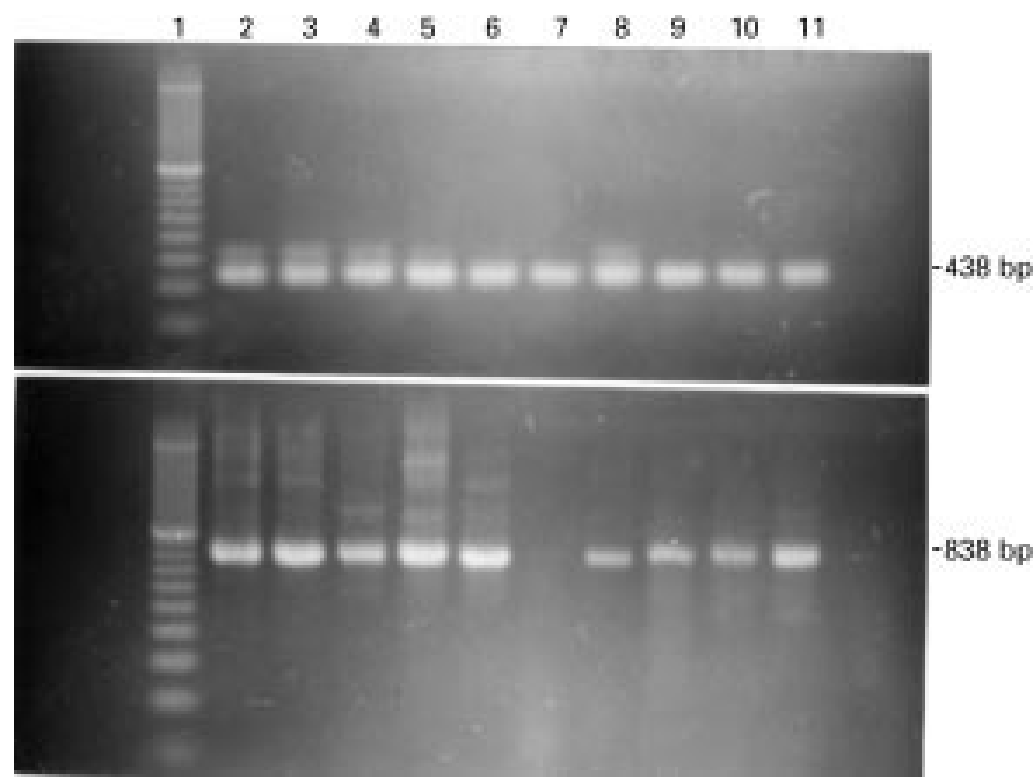

Figure 6 TGF- $\beta 2$ mRNA levels in fetal, normal adult, and glaucomatous eyes, as determined by relative RT-PCR. Similar levels of TGF- $\beta 2 m R N A$ were observed in all samples tested (upper), when compared with $\beta$ actin levels (lower). Lane 1, molecular weight marker (100 bp ladder, FMC Products); lane 2, cultured human brain astrocytes; lane 3, cultured type 1B astrocytes; lanes 4 and 5, fetal optic nerve heads, 19 and 20 weeks gestational age; lanes 6-8, normal adult optic nerve heads, donor ages 66, 88, and 94 years old; lanes 9-11, glaucomatous optic nerve heads, donor ages 53, 67, and 92 years old.

TGF- $\beta 2$ GENE EXPRESSION

To determine TGF- $\beta 2$ mRNA levels, we performed relative RT-PCR in samples from fetal, normal and glaucomatous eyes. Our results demonstrated that TGF- $\beta 2 \mathrm{mRNA}$ is expressed at very low levels (approximately seven orders of magnitude lower than $\beta$ actin) with no apparent differences in the mRNA levels between the different groups analysed (Fig 6). When amplified with TGF- $\beta 2$ primers, some samples, notably from cultured cells, presented another product approximately 50 bp larger, probably due to alternative splicing of this region. ${ }^{16}$

\section{Discussion}

This study used two different approaches to demonstrate the presence of TGF- $\beta$ in tissues of the human optic nerve head in glaucoma: (1) immunolocalisation of TGF- $\beta 1, \mathrm{TGF}-\beta 2$, and TGF- $\beta 3$ at the light microscopic level, and (2) bioassay of TGF- $\beta 1$ and TGF- $\beta 2$ in freshly explanted optic nerve heads. Our results indicate that TGF- $\beta 2$ is specifically and predominantly synthesised in the optic nerve head of glaucomatous and fetal eyes. TGF- $\beta 1$ was only detected by immunocytochemistry in association with blood vessels in glaucomatous optic nerve heads, and no TGF- $\beta 1$ was present in detectable quantities by bioassay. We were unable to detect specific immunoreactivity against TGF- $\beta 3$ in the samples tested.

The results presented here using immunohistochemistry were consistent in all samples analysed. The specificity of the TGF- $\beta 2$ antibody and the high level of TGF- $\beta 2$ activity from optic nerve heads of glaucomatous eyes indicate an enhanced level of TGF- $\beta 2$ protein synthesis by astrocytes of the optic nerve head in glaucomatous optic nerve heads. There was qualitatively more TGF- $\beta 2$ labelled astrocytes in optic nerve heads with advanced glaucoma compared with those with mild glaucoma. Because immunohistochemistry is not a quantitative technique, we cannot make a correlation between immunohistochemical results and the extent of the visual field loss in this study.

Using relative RT-PCR, we detected TGF- $\beta 2$ mRNA in fetal, normal, and glaucomatous optic nerve heads. We did not observe any apparent differences in TGF- $\beta 2$ mRNA levels between the groups studied. Our RTPCR assay does not allow absolute quantitation. However, these results are in accordance with other studies that demonstrate that TGF- $\beta 2$ mRNA level does not parallel protein synthesis and/or bioavailability, providing evidence for post-transcriptional regulation of TGF- $\beta 2 .{ }^{17}{ }^{18}$

TGF- $\beta$ regulates embryonic development of the central and peripheral nervous system and has a role in proliferation and differentiation of neurons and glia. ${ }^{3}$ During development of murine CNS, TGF- $\beta 1$ is expressed almost exclusively in leptomeninges, whereas TGF- $\beta 2$ and TGF- $\beta 3$ are expressed by differentiating neurons and glia, as well as in cranial nerve fibres and in cranial and dorsal root ganglia. In these tissues there is evidence that TGF- $\beta 2$ and TGF- $\beta 3$ may modulate neuronal mobility, placement, and differentiation. ${ }^{19}$ In this study, we were unable to detect TGF- $\beta 3$ by immunohistochemistry in the fetal samples analysed. TGF- $\beta 2$ was associated with glial cells, vascular cells, and scleral fibroblasts in fetal samples. The levels of TGF- $\beta 2$, as measured by bioassays, from fetal optic nerve heads were 90-100-fold greater than normal adult optic nerve heads, suggesting a role for this cytokine in the development of the optic nerve head.

In glaucomatous optic nerve heads there is nearly a 100-fold increase in the level of TGF- $\beta$ and the isotype is limited to TGF- $\beta 2$. TGF- $\beta 2$ isotype has been found to be associated with neurons and glial cells in the central nervous system. Astrocytes from the human brain immunoreact with both TGF- $\beta 1$ and TGF- $\beta 2$ antibodies, but no reactivity for TGF- $\beta 3$ is found. ${ }^{20}$ In the eye, TGF- $\beta 2$ has been demonstrated to be the predominant TGF- $\beta$ isoform present in the neural retina, retinal pigment epithelium, choroid, and in the vitreous of monkey eyes. ${ }^{21}$ In addition, TGF- $\beta 2$ has been detected as the only isoform of TGF- $\beta$ in aqueous humour. ${ }^{22}$ The finding of TGF- $\beta 2$ as the predominant secreted isoform in the optic nerve head suggests that TGF- $\beta 2$ is probably synthesised by neuroglial cells; the absence of detectable levels of TGF- $\beta 1$ in our bioassay indicates that there is probably no participation of blood borne cells or factors and supports the hypothesis of local production of TGF- $\beta 2$ in the optic nerve head.

In the glaucomatous optic nerve head TGF- $\beta 2$ localises to reactive astrocytes, which line the vitreal surface and occupy the prelaminar region, the compressed cribriform plates, and nerve bundles in the lamina cribrosa. These astrocytes are characterised by cellular hypertrophy, increased GFAP immunoreactivity, and round cell bodies with retracted cell 
processes. These reactive astrocytes migrate from the core of the cribriform plates into the nerve bundles. ${ }^{15}$ The antibody against TGF- $\beta 2$ demonstrated strong reactivity in the cytoplasm of the astrocytes in the glaucomatous optic nerve heads, which were located inside the nerve bundles. Like most cytokines, TGF- $\beta$ is not stored in the cells, suggesting that our finding of intracellular TGF- $\beta 2$ staining represents new synthesis of the growth factor during glaucomatous optic neuropathy. In addition, the appearance of high levels of TGF- $\beta$ in the supernatant of the optic nerve explants indicates that the cytokine is secreted in copious amounts in fetal and glaucomatous tissue. Though we cannot differentiate between active and latent TGF- $\beta$ in this study, the fact that there is more total TGF- $\beta$ in fetal and glaucoma eyes suggests that there is presumably more available TGF- $\beta$ that can be activated to exert its effects in these tissues. TGF- $\beta$ has also been selectively localised to reactive astrocytes in CNS lesions resulting from multiple sclerosis and Alzheimer's disease, where TGF- $\beta 2$ is the principal isoform represented. ${ }^{20}{ }^{23}$ While some in vitro studies have suggested that TGF- $\beta$ expression may potentiate neuronal injury, others have demonstrated that increased astroglial expression of TGF- $\beta 2$ may protect neurons from damage during the process of Alzheimer's disease and Parkinson's disease, possibly by reducing inflammation. ${ }^{24}$

It remains to be determined whether TGF- $\beta$ offers neuroprotection or potentiates injury to the retinal ganglion cell axons in the glaucomatous optic nerve head. In contrast with Alzheimer's and Parkinson's diseases, there is no evidence for an inflammatory process in glaucomatous optic neuropathy. Nevertheless, in glaucoma, TGF- $\beta$ may be involved in the optic neuropathy through other mechanisms, including the modulation of optic nerve head astrocyte responses and regulation of extracellular matrix production and tissue remodelling.

An important function of TGF- $\beta$ in modulating astrocyte responses is the induction of the reactive phenotype, ${ }^{25}$ which is part of the wound healing process in the CNS. In addition to morphological changes, reactive astrocytes synthesise more ECM and adhesion molecules, participating in tissue remodelling after injury. ${ }^{1426} \mathrm{TGF}-\beta$ is known to modulate tissue remodelling by upregulating the synthesis of most extracellular matrix proteins, including fibronectin, collagens, proteoglycans, and tropoelastin, and decreasing the production of extracellular matrix proteases. ${ }^{27-30}$ In glaucoma there is extensive remodelling of the extracellular matrix ${ }^{31-33}$ with enhanced synthesis and gene expression of matrix components such as collagen IV and tropoelastin by optic nerve head astrocytes. ${ }^{9} 1034$ Although the mechanism of upregulation of these genes in glaucoma is unknown, TGF- $\beta$ may be one of the key modulators of extracellular matrix gene expression by astrocytes. Similar effects of TGF- $\beta$ have been described also during tissue fibrosis, lung emphysema, and systemic sclerosis. ${ }^{263536}$

In summary, our study demonstrates, through immunohistochemistry and bioassay, the secretion of TGF- $\beta 2$ in fetal and adult glaucomatous human optic nerve head and localises this growth factor to the astrocytes in the prelaminar region and lamina cribrosa. Owing to the broad activity of TGF- $\beta$ s on cell proliferation, differentiation, migration, and extracellular matrix remodelling in neural injury and wound repair in the CNS, TGF- $\beta 2$ may be one of the local factors responsible for activation of astrocytes and remodelling of the optic nerve head in glaucoma. Whether synthesis of TGF- $\beta 2$ is a primary or a secondary response to the loss of axons in glaucoma or whether TGF- $\beta 2$ may play a protective role in the neuropathy, is unknown. These findings represent a first step to a better comprehension of the cascade of cellular events that results in remodelling of the extracellular matrix in the glaucomatous optic nerve head.

Supported by NIH grants EY02687 and EY06416, Research to Prevent Blindness (MRH), and The Glaucoma Foundation, Prevent Blindness

1 Hernandez MR, Pena JDO. The optic nerve head in glaucomatous optic neuropathy. Arch Ophthalmol 1997;115:38995.

2 Roberts $\mathrm{AB}$, Heine UI, Flanders KC, et al. Transforming growth factor- $\beta$ - major role in regulation of extracellular matrix. Ann NY Acad Sci 1990;580:225-32.

3 Krieglstein K, Rufer M, Suter-Crazzolara C, et al. Neural functions of the transforming growth factors $\beta$. Int $\mathcal{F} D$ er Neurosci 1995;13:301-15.

4 Pasquale LR, Dorman-Pease ME, Lutty GA, et al. Immunolocalization of TGF- $\beta 1,-\beta 2$, and $\beta 3$ in the anterior segment of the human eye. Invest Ophthalmol Vis Sci 1993; 34:23-30.

5 Anderson DH, Guérin CJ, Hageman GS, et al. Distribution of transforming growth factor- $\beta$ isoforms in the mammalian retina. F Neurosci Res 1995;42:63-79.

6 Tripathi BJ, Li J, Chalam KV, et al. Upregulated expression of gamma-interferon and transforming growth factor- $\beta 1$ in the optic nerve head of glaucomatous eyes. ARVO Abstracts. Invest Ophthalmol Vis Sci 1996;37:S411.

7 Gupta A, Bazer FW, Jaeger LA. Differential expression of beta transforming growth factors (TGF $\beta 1$, TGF $\beta 2$, and TGF 33 ) and their receptors (type I and type II) in peri-implantation porcine conceptuses. Biol Reprod 1996; 55:796-802.

8 Frank S, Madlener M, Werner S. Transforming growth factors $\beta 1, \beta 2$, and $\beta 3$ and their receptors are differentially tors $\beta 1, \beta 2$, and $\beta 3$ and their receptors are differentially regulated during normal and imp

9 Hernandez MR, Ye H, Roy S. Collagen type IV gene expression in human optic nerve heads with primary open angle glaucoma. Exp Eye Res 1994;59:41-52.

10 Hernandez MR, Yang J, Ye H. Activation of elastin mRNA expression in human optic nerve heads with primary openangle glaucoma. F Glaucoma 1994;3:214-25.

11 Granstein RD, Staszewski R, Knisely TL, et al. Aqueous humor contains transforming growth factor-beta and a small (less than 3500 Daltons) inhibitor of thymocyte proliferation. F Immunol 1990;144:3021-7.

12 Takeuchi M, Kosiewicz MM, Alard P, et al. On the mechanisms by which transforming growth factor-beta 2 alters antigen-presenting abilities of macrophages on T cell activation. Eur f Immunol 1997;27:1648-56.

$13 \mathrm{Ye} \mathrm{H}$, Hernandez MR. Heterogeneity of astrocytes in human optic nerve head. $\mathcal{F}$ Comp Neurol 1995;362:441-52.

4 Norenberg MD. Reactive astrocytosis. In: Aschner M, Norenberg MD. Reactive astrocytosis. In: Aschner M,
Kimelberg HK, eds. The role of glia in neurotoxicity. Boca Raton: CRC Press, 1996:93-107.

15 Varela H, Hernandez MR. Astrocyte response in human optic nerve head with primary open-angle glaucoma. $\mathcal{F}$ Glaucoma 1997;6:303-13.

16 Webb NR, Madisen L, Rose TM, et al. Structural and sequence analysis of TGF-beta 2 cDNA clones predicts two different precursor proteins produced by alternative mRNA splicing. DNA 1988;7:493-7.

17 Bodmer S, Strommer K, Frei K, et al. Immunosuppression and transforming growth factor- $\beta$ in glioblastoma, preferential production of transforming growth factor-beta 2.7 Immunol 1989;143:3222-9.

18 Constam DB, Philipp J, Malipiero UV, et al. Differential expression of transforming growth factor-beta 1 , -beta 2 and -beta 3 by glioblastoma cells, astrocytes, and microglia. f Immunol 1992;148:1404-10. 
19 Johnson MD, Jennings, MT, Gold LI, et al. Transforming growth factor- $\beta$ in neural embryogenesis and neoplasia. Hum Pathol 1993;24:457-62.

20 Flanders KC, Lippa CF, Smith TW, et al. Altered expression of transforming growth factor- $\beta$ in Alzheimer's disease. Neurology 1995;45:1561-9.

21 Pfeffer BA, Flanders KC, Guérin CJ, et al. Transforming growth factor beta 2 is the predominant isoform in the neural retina, retinal pigment epithelium-choroid and vitreous in the monkey eye. Exp Eye Res 1994;59:323-33.

22 Cousins SW, McCabe MM, Danielpour D, et al. Identification of transforming growth factor- $\beta$ as an immunosuppressive factor in aqueous humor. Invest Ophthalmol Vis Sci 1991;32:2201-11.

23 Peress NS, Perillo E, Seidman RJ. Glial transforming growth factor (TGF)- $\beta$ isotypes in multiple sclerosis: differential sclerosis. F Neuroimmunol 1996;71:115-23.

24 Flanders KC, Ren RF, Lippa CF. Transforming growth factors-bs in neurodegenerative disease. Prog Neurobiol 1998;54:71-85

25 Flanders KC, Lüdecke G, Renzig J, et al. Effect of TGF- $\beta$ s and bFGF on astroglial cell growth and gene expression in vitro. Mol Cell Neurosci 1993;4:406-17.

26 Ridet JL, Malhotra SK, Privat A, et al. Reactive astrocytes: cellular and molecular cues to biological function. Trends Neurosci 1997;20:570-7.

27 Border WA, Noble NA. Transforming growth factor $\beta$ in tissue fibrosis. N Engl f Med 1994;331:1286-92.

28 Katchman SD, Hsu-Wong S, Ledo I, et al. Transforming growth factor- $\beta$ up-regulates human elastin promoter activity in transgenic mice. Biochem Biophys Res Comm 1994;203:485-90.

29 Kucich U, Rosenbloom JC, Abrams WR, et al. Stabilization of elastin mRNA by TGF- $\beta$ : Initial characterization of signaling pathway. Am f Respir Cell Mol Biol 1997;17:10-16.

30 Kähäri VM, Olsen DR, Rhudy RW, et al. Transforming growth factor- $\beta$ up-regulates elastin gene expression in human skin fibroblasts. Evidence for post-transcriptional modulation. Lab Invest 1992;66:580-8.

31 Hernandez MR, Andrzejewska WM, Neufeld AH. Changes in the extracellular matrix of the human optic nerve head in primary open-angle glaucoma. Am f Ophthalmol 1990;109; 180-8.

32 Morrison JC, Dorman-Pease ME, Dunkelberger GR, et al. Optic nerve head extracellular matrix in primary optic atrophy and experimental glaucoma. Arch Ophthalmol 1990;108;1020-4.

33 Fukuchi T, Sawaguchi S, Hara H, et al. Extracellular matrix changes of the optic nerve lamina cribrosa in monkey eyes with experimentally chronic glaucoma. Graefes Arch Clin Exp Ophthalmol 1992;230:421-7.

34 Pena JDO, Roy S, Hernandez MR. Tropoelastin gene expression in optic nerve heads of normal and glaucomatous subjects. Matrix Biol 1996;15:323-30.

35 Pierce RA, Mariani TJ, Senior, RM. Elastin in lung development and disease. Ciba Found Symp 1995;192:199212.

36 Quaglino D Jr, Bergamini G, Boraldi F, M et al. Connective tissue in skin biopsies from patients suffering systemic sclerosis. F Submicrosc Cytol Pathol 1996;28:287-96. 